\title{
Multichannel Detection of Photoacoustic Signals: Preliminary Results
}

\author{
Piotr Zbysiński ${ }^{1}$. Tomasz Starecki
}

Received: 6 December 2014 / Accepted: 29 June 2015 / Published online: 15 July 2015

(C) The Author(s) 2015. This article is published with open access at Springerlink.com

\begin{abstract}
In a typical photoacoustic measurement system, signal detection is usually implemented with a single microphone or another pressure sensor. A solution presented in this paper consists of an array of 14 MEMS microphones equipped with dedicated and individually controllable signal paths, based on programmable gain amplifiers and analog-to-digital converters. Further, digital signal processing and recording are implemented in an FPGA-based hardware system. Use of multiple microphones increases the signal amplitude and the signal-to-noise ratio and allows for measurements of pressure-field distribution inside the photoacoustic cell.
\end{abstract}

Keywords Configurable hardware $\cdot$ MEMS microphone $\cdot$ Multichannel photoacoustic measurements - Multichannel signal recording $\cdot$ Multipoint signal averaging $\cdot$ Photoacoustic equipment

\section{Introduction}

In a traditional photoacoustic setup (Fig. 1), an investigated sample is placed in an enclosed cell. Stimulation of the sample with a modulated light beam induces a photoacoustic signal, for which the amplitude and phase can be measured by means of a pressure sensor, e.g., microphone [1-3]. In typical photoacoustic equipment, signal

Tomasz Starecki

tomasz@starecki.com; t.starecki@ise.pw.edu.pl

Piotr Zbysiński

piotr.zbysinski@btc.pl

1 BTC Korporacja, Legionowo, Poland

2 Institute of Electronic Systems, Warsaw University of Technology, Nowowiejska 15/19, 00-665 Warsaw, Poland 


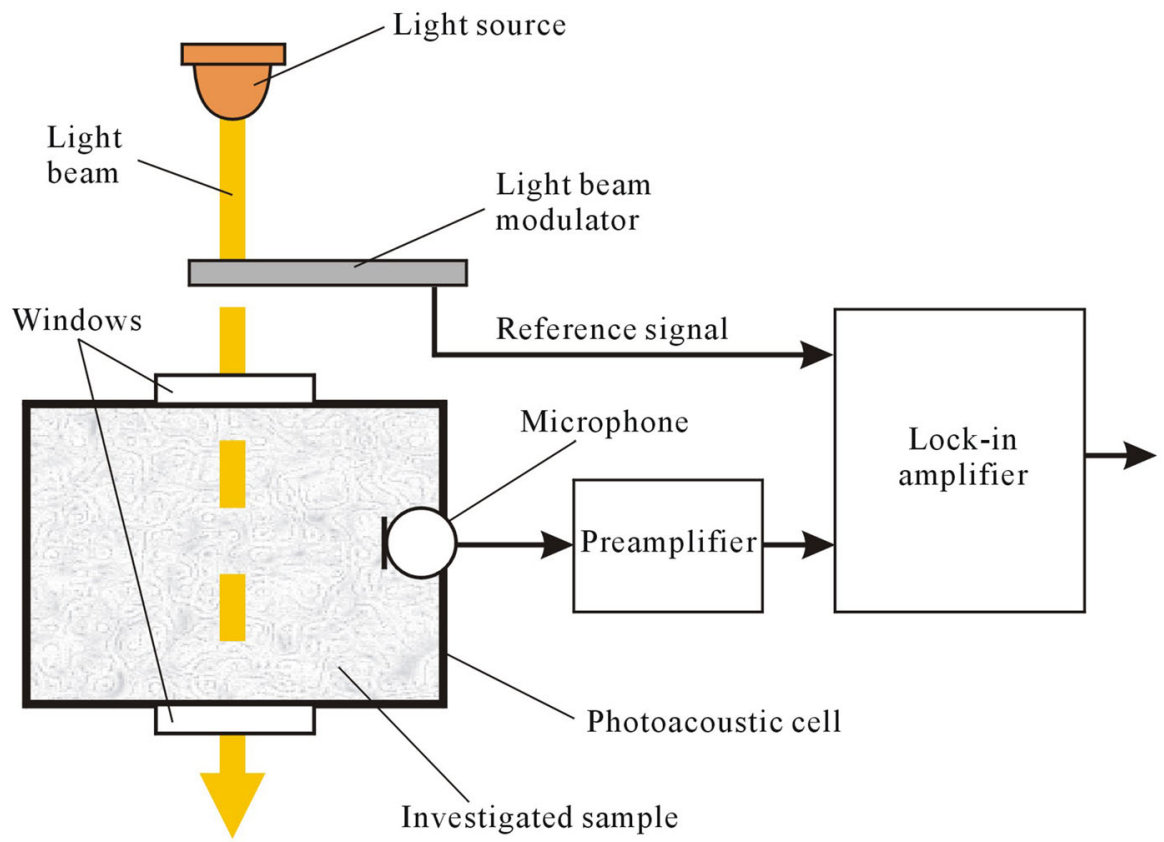

Fig. 1 Structure of a typical photoacoustic system based on a single microphone

detection is usually implemented with a single microphone or another pressure sensor. Use of multiple microphones is a less common solution, limited nearly exclusively to setups with differential signal detection [4-7]. In such a case two microphones are used, one placed in the measuring cell, and the other in the reference cell which is not stimulated with light (Fig. 2a) [4,5]. Taking into consideration that the photoacoustic signal is induced in the measuring cell only, while the external noise reaches both cells, subtraction of the signals from the microphones results in substantial reduction of the external acoustic noise. Some variants of the differential setups use a single cell in which the microphones are located in such a way that they sense the photoacoustic signal with a phase difference (Fig. 2b) [5-7]. Photoacoustic measurements with simple summing of the signals from multiple microphones placed in a single cell have been also reported [8-10]. Such solutions allow for an increase of the output signal but are rarely implemented, as in the case of a standard condenser or an electret microphone, the best ratio of sensitivity-to-membrane area is obtained for $1 / 2 \mathrm{in}$. $(1.27 \mathrm{~cm})$ microphones, which are already considered as relatively big when compared to the size of typical photoacoustic cells. These constraints can be easily overcome with a solution based on MEMS microphones.

\section{Multichannel Detection Concept and Test Circuitry}

Condenser microphones based on MEMS solutions (MEMS stands for micro-electromechanical systems; these micro-scale electro-mechanical devices are manufactured 
(a)

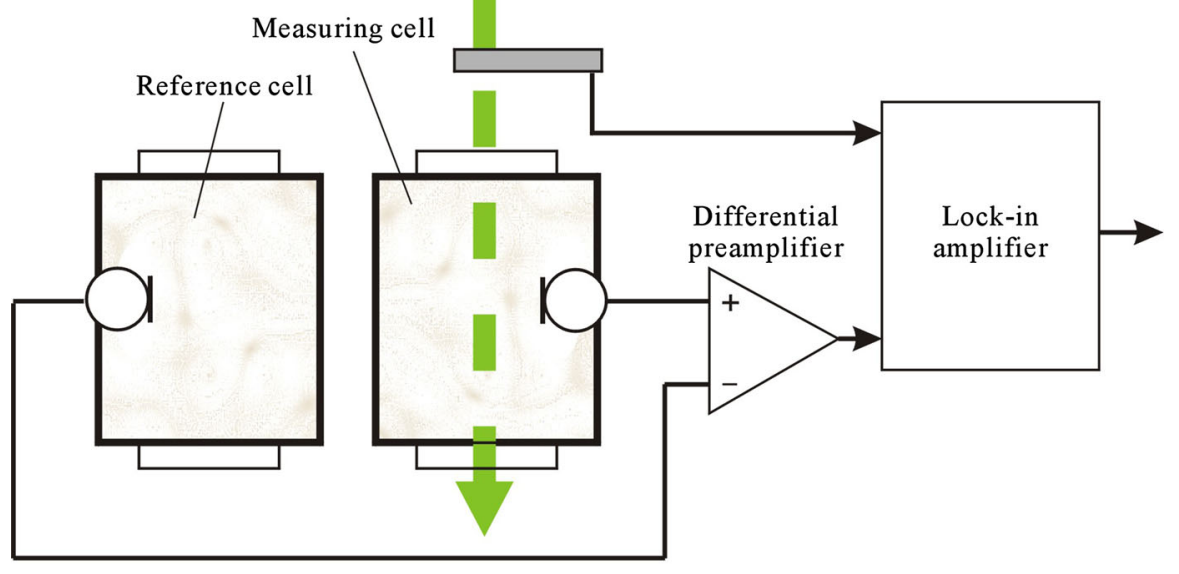

(b)
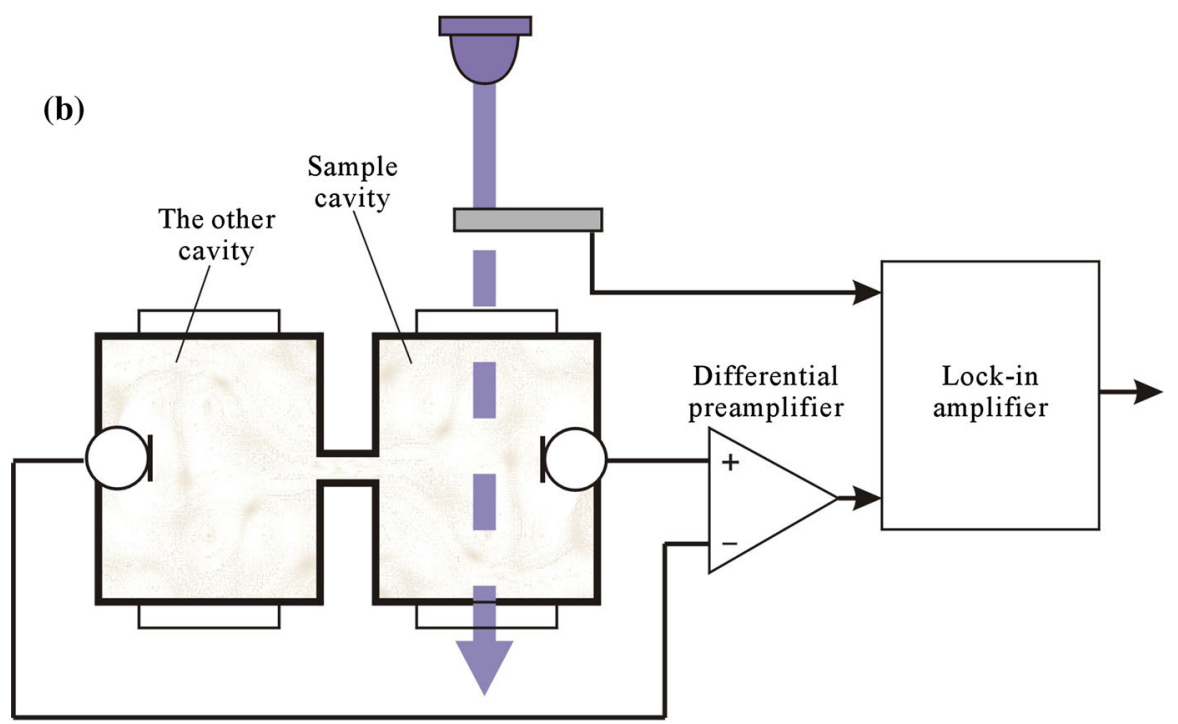

Fig. 2 Structure of a differential photoacoustic detection setup: with (a) a reference cell and (b) a Helmholtz resonator

with methods and technologies used in production of semiconductor circuits) have gained a substantial part of the microphone market share. Their main advantages are low cost, good specifications, and small size. Commercially available MEMS microphones can be as small as $1.85 \mathrm{~mm} \times 2.75 \mathrm{~mm}$, and at the mentioned size, they have a sensitivity of about $12.5 \mathrm{mV} \cdot \mathrm{Pa}^{-1}$ (e.g., SPV 1840 model produced by Knowles) [11]. A similar sensitivity is typical for many pressure-field $1 / 2 \mathrm{in}$. $(1.27 \mathrm{~cm})$ microphones (e.g., Bruel\&Kjaer 4134, 4180, 4192, 4193) [12,13]. Thus, taking into consideration 


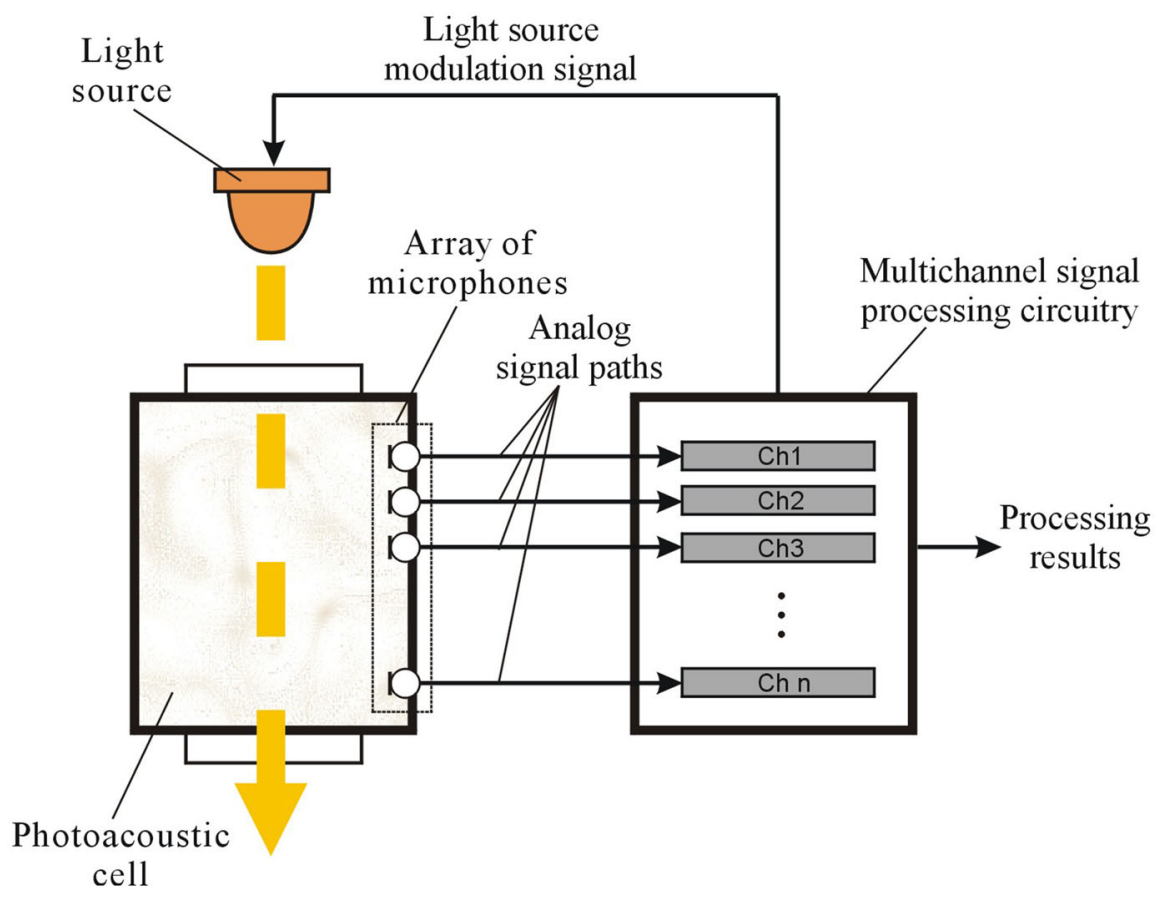

Fig. 3 Block diagram of the designed photoacoustic system with an array of MEMS microphones

that the membrane area of a $1 / 2 \mathrm{in} .(1.27 \mathrm{~cm})$ microphone is equivalent to the area occupied by 24 MEMS microphones of the size given above, it is possible to obtain a substantial increase of the sensitivity if the condenser/electret microphone is replaced by an array of such MEMS microphones.

The concept of the multi-microphone signal detection was tested with a hardware solution presented in Fig. 3. Instead of a single microphone, an array of 14 MEMS microphones (SPU0410LR5H with a sensitivity of $12.5 \mathrm{mV} \cdot \mathrm{Pa}^{-1}$, produced by Knowles [14]) was used. Each microphone has its individual analog signal path (channel) for which details are shown on a block diagram presented in Fig. 4. The signal path consists of a programmable gain amplifier (PGA113 with the gain digitally programmable from $1 \mathrm{~V} / \mathrm{V}$ to $200 \mathrm{~V} / \mathrm{V}[15,16]$ ), an analog low-pass filter (placed in the external feedback loop of the PGA), a 12 bit A/D converter (AD7091 [17]), and a multipoint signal averaging circuit (Fig. 5) [18] implemented in a Cyclone IV FPGA (FPGA stands for field-programmable gate array, which is a programmable and fully reconfigurable integrated circuit, for which resources can be sufficient for implementation of very complex and mostly digital circuits, e.g., microprocessors, digital filters, etc.). As a result, in such a circuit it is possible to analyze properties (e.g., shape, amplitude, and phase) of the signals from all the microphones independently. The multichannel multipoint averaging circuit produces a light modulation control signal and appropriately synchronized all the control signals required by the A/D converters. The signal from every channel is recorded and stored in a separate RAM 


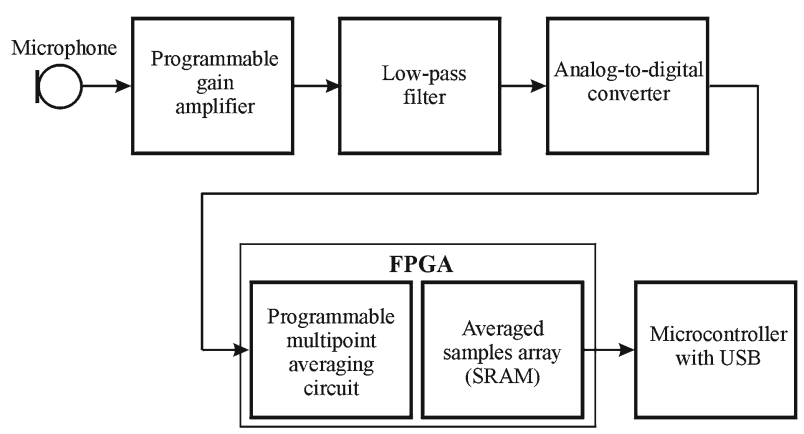

Fig. 4 Block diagram of a single-signal channel in the designed system

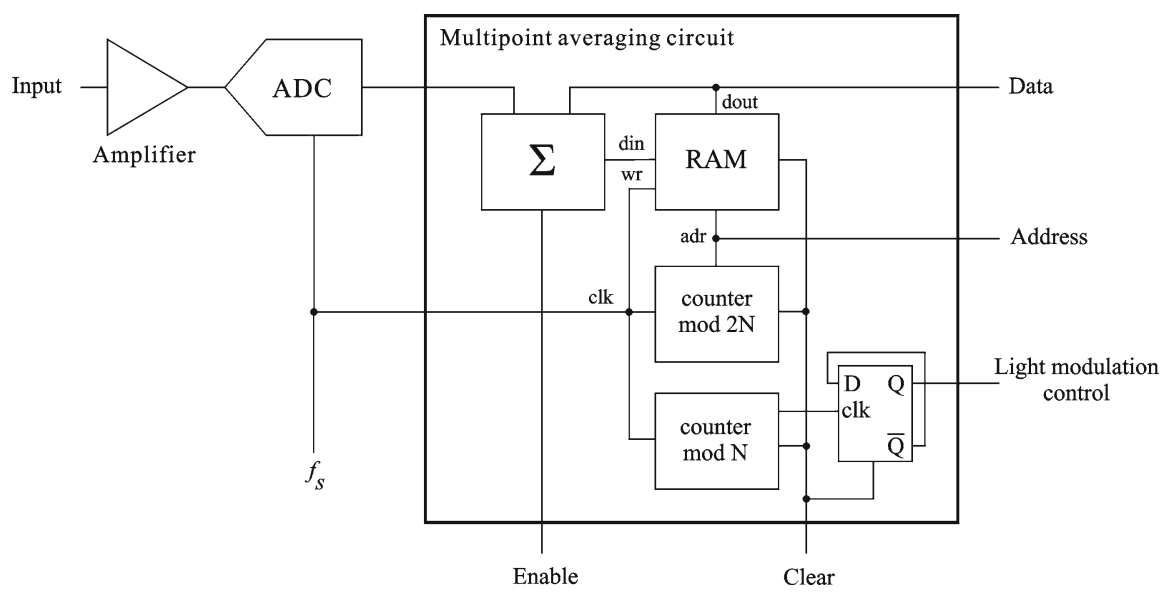

Fig. 5 Block diagram of a multipoint signal averaging circuit, producing synchronized light modulation control signal, implemented in FPGA

memory block. The multipoint averaging structure implemented in the FPGA allows for an independent configuration of all the digital signal paths (i.e., averaging factors, number of acquired samples, etc.). It should be also noticed that due to the use of the FPGA, it is very easy to implement additional, digital signal processing, independent for every channel. Such signal processing may include digital filtering, amplification/attenuation of the signal, phase shifting, etc. Taking into consideration that every signal path can have individually selected properties (e.g., frequency responses of the filters, attenuation/gain factors, etc.), such a feature can be used for the purpose of individual, digital adjustment of the signal paths without the need of precise, thus difficult, time-consuming and expensive analog tuning.

The FPGA project was developed with a Quartus II environment. The structure implemented in the FPGA uses less than $25 \%$ of available logic resources; thus, there is a lot of room for future enhancements. The recorded signals can be read, and all the settings of the test hardware are controlled by a 32 bit microcontroller (STM32 with ARM Cortex-M3 core [19]), equipped with a USB interface, which is fully supported by all the popular operating systems (e.g., Windows XP/7/8 or Linux). Thus, the user 


\section{Array of microphones}

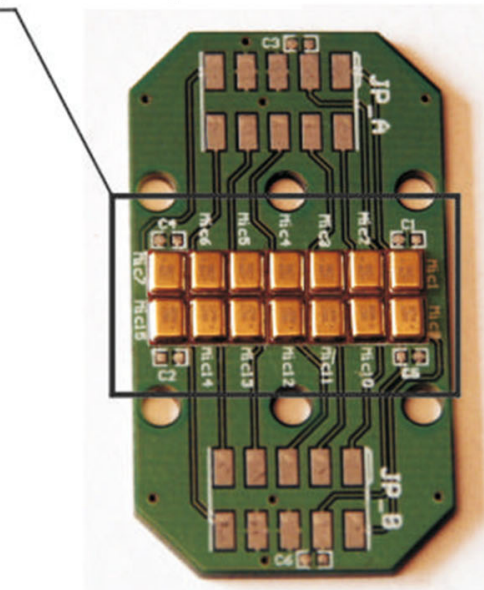

Acoustic ports (drilled in PCB)

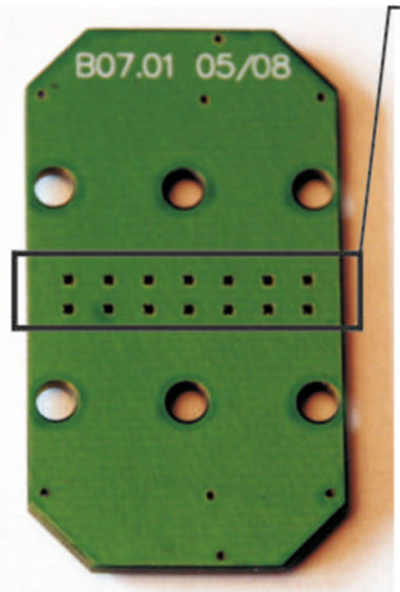

Fig. 6 Photo of the MEMS microphones array board

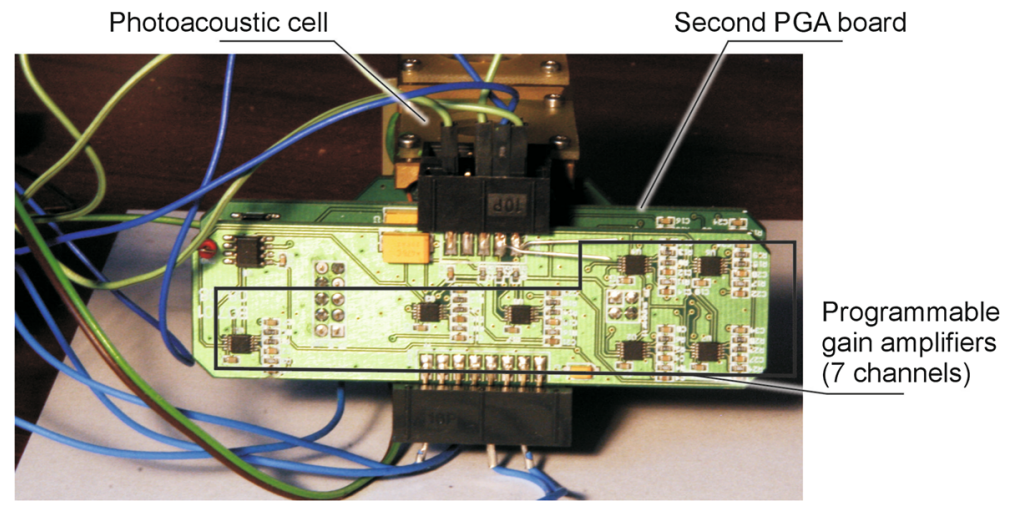

Fig. 7 Photo of the analog front-end circuitry

gets easy access to all the recorded signal data and configuration settings of the test hardware.

Mechanical structure of the developed printed circuit board (PCB) with assembled MEMS microphones is shown in Fig. 6. The microphones are placed in an array of two columns by seven rows as close to each other as possible. The microphones have bottom acoustic ports. There are no components mounted at the bottom PCB layer, resulting in a flat PCB surface, so that it does not introduce any additional disturbance to the gas flow inside the cell, and can be easily sealed to the body of the photoacoustic cell. The acoustic ports of the microphones are located inside a $20 \mathrm{~mm} \times 5 \mathrm{~mm}$ rectangle. The input analog circuitry is divided into three PCBs (Fig. 7). The microphones are assembled on the first board, while the two other boards contain the programmable gain amplifiers, low-pass filters, and A/D converters. 


\section{Experimental Results}

For the purpose of preliminary tests, a symmetrical Helmholtz cell with both cavities having the form of cylinders $30 \mathrm{~mm}$ high and $8 \mathrm{~mm}$ in diameter was used. The light source was an LED diode emitting about $50 \mathrm{~mW}$ at $940 \mathrm{~nm}$ on a carbon black sample. The microphones were placed in the same cavity as the sample. Signals from all the microphones were recorded synchronously, with a resolution of 100 samples per period. The light modulation frequency was set initially at $300 \mathrm{~Hz}$, at which signals from all the microphones have a virtually identical amplitude and phase. Further observations were performed with the light modulation frequency gradually increased. Results of the measurements obtained with the light beam modulation at a frequency of $10 \mathrm{kHz}$ are shown in Fig. 8. The photoacoustic signal measured at different points

(a)

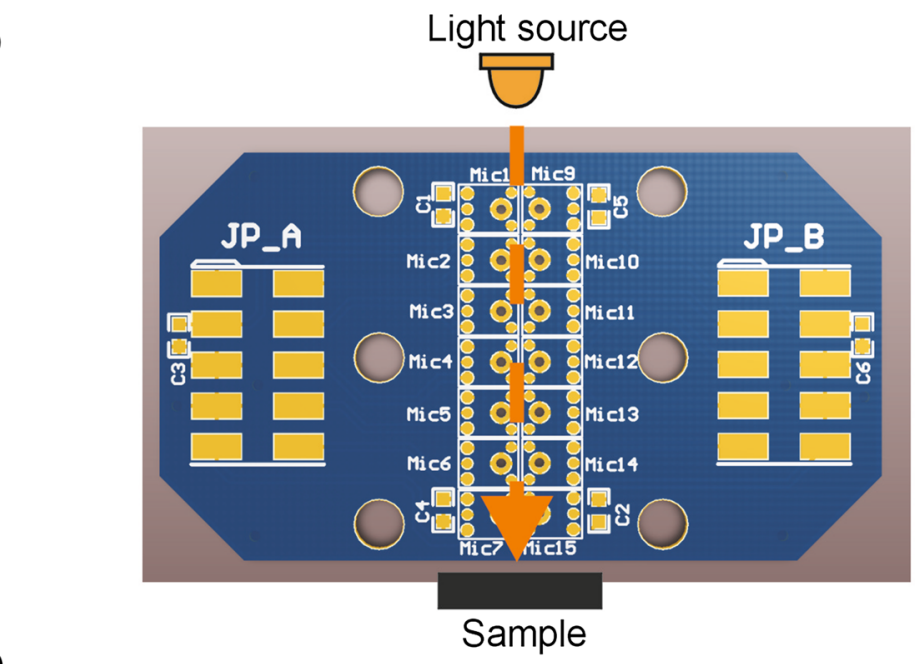

(b)

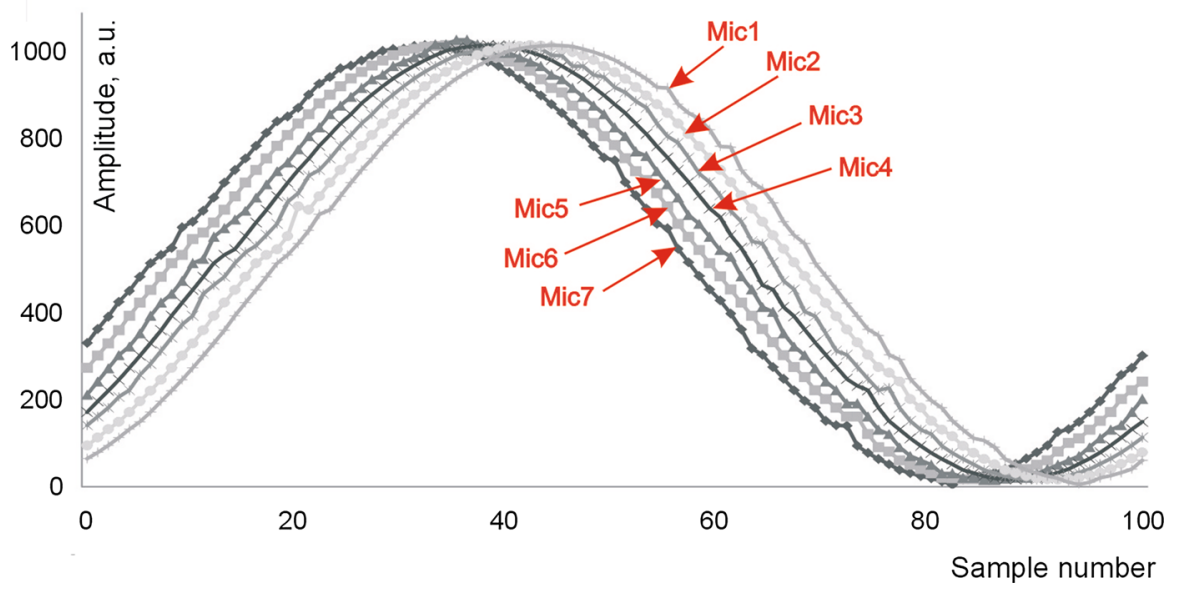

Fig. 8 (a) Placement of the microphones referred to the location of the light source and the sample and (b) measurement results showing phase difference of the signals from the microphones 
across the height of the photoacoustic cell exhibits a noticeable phase shift. This is clear proof that in addition to higher sensitivity resulting from summing the signals from multiple microphones and an increase of the signal-to-noise ratio due to averaging, the described concept of multichannel detection of photoacoustic signals allows for measurements of the acoustic field distribution inside the cell.

\section{Conclusions}

In this paper we presented a concept of multichannel detection of photoacoustic signals based on the use of an array of MEMS microphones. The solution substantially increases the sensitivity of the setup and allows for signal-to-noise ratio improvement by summing signals from several microphones. Due to the small size of the microphones, the array can be formed in virtually any shape (e.g., rectangle); thus, it is possible to adjust it to a particular mechanical design of the photoacoustic cell. In addition, the proposed solution allows not only for measurements of the average pressure changes in the cell as in the case of a single microphone (or multiple microphones with simple analog summing of the signals), but also for determination of the acoustic signals at many points inside the photoacoustic cell. Thus, it is possible to measure an acoustic field distribution, which may be very helpful, e.g., in the analysis of the behavior of small acoustic structures such as small photoacoustic Helmholtz resonators. Other important advantages of the presented solution are a very good priceto-performance ratio and high flexibility due to implementation of the digital part in the form of reconfigurable, programmable logic based on an FPGA and microcontroller.

Open Access This article is distributed under the terms of the Creative Commons Attribution 4.0 International License (http://creativecommons.org/licenses/by/4.0/), which permits unrestricted use, distribution, and reproduction in any medium, provided you give appropriate credit to the original author(s) and the source, provide a link to the Creative Commons license, and indicate if changes were made.

\section{References}

1. L.B. Kreuzer, J. Appl. Phys. 42, 2934 (1971)

2. V.P. Zharov, V.S. Letokhov, Laser Optoacoustic Spectroscopy, Chaps. 2, 5 (Springer, Berlin, 1986)

3. T. Starecki, Selected Aspects of Photoacoustic Instruments Optimization, Chap. 4 (BTC, Legionowo, 2009). doi:10.13140/2.1.4514.9761 (in Polish)

4. A. Schmohl, A. Miklós, P. Hess, Appl. Opt. 41, 1815 (2002)

5. V.A. Kapitanov, V. Zeninari, B. Parvitte, D. Courtois, Yu.N. Ponomarev, Spectrochim. Acta A 58, 2397 (2002)

6. S.V. Egerev, A.V. Fokin, A.E. Pashin, Rev. Sci. Instrum. 67, 2691 (1996)

7. T. Starecki, A. Geras, Int. J. Thermophys. 35, 2259 (2014)

8. M. Nägele, D. Hofstetter, J. Faist, M.W. Sigrist, Anal. Sci. 17, s497 (2001)

9. J. Davidsson, J.H. Gutow, R.N. Zare, J. Phys. Chem. 94, 4069 (1990)

10. J. Li, K. Liu, W. Zhang, W. Chen, X. Gao, Opt. Appl. 38, 341 (2008)

11. Knowles, SPV1840LR5H-B Data Sheet, Revision B. (2014). http://www.knowles.com. Accessed 6 July 2015

12. Bruel\&Kjaer, Product Data, Condenser Microphone Cartridges-Types 4133 to 4181 . http://www. bksv.com. Accessed 6 July 2015 
13. Bruel\&Kjaer, Product Data, 1/2-inch Pressure-Field Microphone-Type 419x. http://www.bksv.com. Accessed 6 July 2015

14. Knowles, SPU0410LR5H-QB Data Sheet, Revision H. (2013). http://www.knowles.com. Accessed 6 July 2015

15. T. Starecki, Int. J. Thermophys. 35, 2124 (2014)

16. http://www.ti.com/product/pga113. Accessed 6 July 2015

17. http://www.analog.com/ad7091. Accessed 6 July 2015

18. T. Starecki, Eur. Phys. J. Special Topics 154, 363 (2008)

19. http://www.st.com/web/en/resource/technical/document/reference_manual/CD00171190.pdf. Accessed 6 July 2015 